\title{
STUDY ON TRENDS OF ANAEMIA PREVALENCE: REDUCED PREVALENCE: MYTH OR REALITY
}

\author{
Sumathi Natarajan1, Mallika Selvaraj², Prachi Hotchandani ${ }^{3}$
}

1 Professor, Department of Obstetrics and Gynaecology, Madurai Medical College.

${ }^{2}$ Assistant Professor, Department of Obstetrics and Gynaecology, Madurai Medical College.

3 Post Graduate, Department of Obstetrics and Gynaecology, Madurai Medical College.

\section{ABSTRACT}

\section{AIM}

To study the existing prevalence of anaemia in antenatal patients attending OP at GRH, Madurai and to stress that it still holds an important antenatal complication.

\section{METHODOLOGY}

It is an observational study taken at GRH on all antenatal patients attending OPD to find out prevalence of anaemia among them.

\section{RESULTS}

The prevalence of anaemia was found to be $91.42 \%$ indicating that 9 out of 10 patients attending the OPD are anaemic.

\section{CONCLUSION}

In spite of all government initiatives, though the prevalence of severe anaemia might have decreased, but the prevalence of mild and moderate anaemia still remains fairly high.

\section{KEYWORDS}

Anaemia, Pregnancy, Prevalence, Reduction.

HOW TO CITE THIS ARTICLE: Natarajan S, Selvaraj M, Hotchandani P. Study on trends of anaemia prevalence: reduced prevalence: myth or reality. J. Evolution Med. Dent. Sci. 2016;5(59):4112-4115, DOI: 10.14260/jemds/2016/940

\section{INTRODUCTION}

Pregnancy is not just a matter of waiting to give birth, but a joyful and a fulfilling period in a woman's life. It can also be one of the experiences of misery and suffering when complications or adverse circumstances compromise the pregnancy causing ill health or even death. Anaemia is the term used to describe the condition, in which there is a reduction in the concentration of $\mathrm{Hb}$ in the blood stream to a level below $11 \mathrm{gm} / \mathrm{dL}$ for pregnant women; 90\% of all maternal perinatal deaths are linked to anaemia. Favourable pregnancy outcomes occur (30\%-45\%) less often in anaemic mothers and their infants have less than one of a half of normal iron reserves. Anaemia is particularly prominent in developing countries like India where up to $88 \%$ of pregnant women are affected. A high prevalence of anaemia in pregnant was observed in our study also (91.42\%), out of which $25.84 \%$ was mild, $73.81 \%$ was moderate and $0.35 \%$ were severely anaemic. Anaemia is in a way the most common and most highlighted maternal problem on which the government has worked with all possible schemes, availability of Fe and Folic Acid tablets, giving iron sucrose injection, admitting all case of severe anaemia and treating them with transfusion of Blood products. The past decade of obstetric practice has seen a remarkable change in trends of anaemia prevalence. And although the tip of the iceberg, prevalence of severe anaemia has been drastically reduced as is evident from our study also, the major portion of our

Financial or Other, Competing Interest: None.

Submission 13-06-2016, Peer Review 09-07-2016,

Acceptance 16-07-2016, Published 25-07-2016.

Corresponding Author:

Dr. Sumathi Natarajan,

Suba Clinic, 2 Tagore Nagar,

Thiruppalai,

Madurai.

E-mail: sumathibaskaran88@gmail.com

DOI: $10.14260 /$ jemds/2016/940 population (The hidden iceberg is still suffering from mild and moderate degrees of anaemia, which might not be directly responsible for mortality in many cases is still the most important cause of maternal morbidity and perinatal loses due to low birth weight and IUGR.

\section{AIM}

The Aim of the Study is

1. To find the prevalence of anaemia in antenatal patients attending OPD in GRH, Madurai.

2. To stress the magnitude of anaemia still prevailing in our society.

\section{MATERIALS AND METHODS}

The observational study was undertaken at Govt. Rajaji Hospital attached to Madurai Medical College in Obstetrics and Gynaecology Department; 944 number of cases attended antenatal OP; all patients were tested for $\mathrm{Hb}$ by Sahli's Method and were divided into group as per their obstetric code, severity of anaemia, their gestational age, socioeconomic status and the area to which they belonged (Rural or urban). Patients with known haemoglobinopathies like sickle cell anaemia, thalassemia were excluded from the study. While cases with mild degrees of anaemia in all gestational ages were treated on OPD basis with Fe and Folic Acid tablets, cases with severe anaemia (3) and 160 cases with moderate anaemia of gestational age $>36$ weeks were treated with blood transfusion. This itself indicates that in spite of percentage of people with moderate anaemia is $73.51 \%$, a significant number presents near term and can be treated only with blood products to avoid the possible complications. Other patients with moderate anaemia with gestational age $<34$ weeks were treated with Fe and Folic Acid tablets, out of these around 326 patients were nonresponders mostly due to non-compliance were treated with iron sucrose injections ( 3 injections of $100 \mathrm{mg}$ iron sucrose in 
$100 \mathrm{~mL}$ NS each per week was given). Patients showed improvement within 3-4 weeks of treatment commencement.

\section{OBSERVATION AND RESULTS}

- The study was conducted in 944 patients.

- Total No. of patients - 944 .

- Total No. of patients with Anaemia - 863.

\begin{tabular}{|c|c|c|c|}
\hline Obs Code & Primi & Multi & Grand Multi \\
\hline No. of Pts. & 400 & 451 & 12 \\
\hline Percentage & 46.35 & 52.26 & 1.39 \\
\hline & P value & $<0.001$ & Table 1 \\
\hline \multicolumn{4}{|c|}{} \\
\hline
\end{tabular}

There was a significant difference between the primigravida and multigravidas. Repeated pregnancies predispose the patients to anaemia due to lack of stores replenishment. Also blood loss during successive deliveries leave the patient's general health also deteriorated, which turns into a vicious cycle.

\begin{tabular}{|c|c|c|c|}
\hline $\begin{array}{l}\text { Degree of } \\
\text { Anaemia }\end{array}$ & $10-11 \mathrm{gm} \%$ & 7-10 gm\% & $<7$ gm $\%$ \\
\hline No. of Pts. & 223 & 657 & 3 \\
\hline \multirow[t]{2}{*}{ Percentage } & 25.84 & 73.81 & 0.35 \\
\hline & P value & $<0.001$ & \\
\hline \multicolumn{4}{|c|}{ Table 2} \\
\hline
\end{tabular}

In our study maximum number of patients belonged to moderate anaemia category, whereas only 3 patients were found to have severe anaemia. $P$ value was significant showing that our all initiatives and awareness programme have failed to achieve its ultimate goal. The only achievement we have achieved is reduction in number of patients with severe anaemia, which has in a way helped in maternal mortality reduction has not yet reduced morbidity and also the morbidity for patients presenting even with moderate anaemia at term gestation.

\begin{tabular}{|c|c|c|c|}
\hline $\begin{array}{c}\text { Gestational } \\
\text { Age }\end{array}$ & $\begin{array}{c}<20 \\
\text { Weeks }\end{array}$ & $\begin{array}{c}20-34 \\
\text { Weeks }\end{array}$ & $\begin{array}{c}>34 \\
\text { Weeks }\end{array}$ \\
\hline $\begin{array}{c}\text { No. of } \\
\text { patients }\end{array}$ & 52 & 336 & 475 \\
\hline Percentage & 6.03 & 38.93 & 55.04 \\
\hline & P value & $<0.001$ & \\
\hline
\end{tabular}

Maximum patients belonged to third trimester with $\mathrm{p}$ value significant. This shows the ignorance of patients about regular antenatal follow-up as maximum patients were either attending the antenatal OPD for the first time or were referred from nearby PHC as anaemia complicating pregnancy. Most of the cases had a history of noncompliance for Fe tablets. Demand for Fe increases most in third trimester, but only significant stores and prophylactic $\mathrm{Fe}$ tablets taken from the second trimester can help prevent the development of this depletion of $\mathrm{Hb}$ in third trimester. Since third trimester leaves with less time on hand to correct anaemia, it possess the maximum risk of complications for the patients directly presenting to us at this time.

\begin{tabular}{|c|c|c|c|}
\hline Socioeconomic Status & Class III & Class IV & Class V \\
\hline Number of patients & 176 & 514 & 173 \\
\hline Percentage & 20.39 & 59.55 & 20.74 \\
\hline \multicolumn{4}{|c}{ Table 4 } \\
\hline
\end{tabular}

This shows that the socioeconomic status is a major effector on the patients suffering from anaemia. Low socioeconomic status combined with illiteracy and poor diet forms a vicious cycle predisposing to anaemia not only in pregnancy, but also otherwise.

\begin{tabular}{|c|c|c|}
\hline Geographic Area & Rural & Urban \\
\hline Percentage & 65 & 35 \\
\hline \multicolumn{3}{|c|}{ Table 5 } \\
\hline
\end{tabular}

A significant percentage of the population in our study belonged to rural population. Many reasons favour this trend Some of them include lack of awareness, no regular antenatal checkups, deliveries by local dais at home, open defecation leading to infections and worm infestations etc; although less as compared to rural area, even urban area contributes to a significant proportion as well which is mostly due to increased cost of living in urban areas not met by the people belonging to low socioeconomic class. Other causes for anaemia prevalence in urban population are ignorance of maternal health, poor family support, poor diet as well as even noncompliance to Fe tablets.

\section{DISCUSSION}

The importance of good haemoglobin concentration during pregnancy for both the woman and the growing foetus cannot be overemphasized. Being a driving force for oxygen for the mother and foetus, a reduction below acceptable levels can be detrimental to both. Traditionally, anaemia is defined as a decrease in the ability of blood to carry oxygen due to a decrease in the total number of erythrocytes (Each having a normal quantity of haemoglobin), a diminished concentration of haemoglobin per erythrocyte or a combination of both. A haemoglobin concentration below 11.0 gldL or Packed Cell Volume (PCV) of less than $33.0 \%$ is regarded as anaemia during pregnancy by the World Health Organization (WHO). It is one of the most intractable public health problems in developing countries and the commonest complication in pregnancy in sub-Saharan Africa, more so with the advent of the HIV/AIDS pandemic. The WHO estimates that anaemia affects over half of the pregnant women in developing countries. Recent estimates in the developing countries including India put the prevalence at $60.0 \%$ in pregnancy and about $7.0 \%$ of the women are said to be severely anaemic.

The high prevalence and the aetiological factors responsible for anaemia in pregnancy are multiple and their relative contributions are said to vary by geographical area and by season. Anaemia in pregnancy may be relative or absolute. Relative anaemia is a normal physiological phenomenon that occurs in pregnancy due to larger increase in plasma volume (Approximately $45.0 \%$ in singleton and $50.0-60.0 \%$ in twin gestation) than in red cell mass resulting in the well-known physiological anaemia of pregnancy. Absolute anaemia involves a true decrease in red cell mass involving increased red cell destruction as in haemoglobinopathy, malaria and bacterial infection like urinary tract infection; increased red cell loss as in bleeding; or decreased red cell production as in nutritional deficiency or chronic disease. Predisposing factors include young age, grand multiparity, low socioeconomic status, illiteracy, ignorance and short interpregnancy intervals.(1) Infection with hookworm and intestinal helminths causes 
gastrointestinal blood loss resulting in depletion of the iron stores and consequently impaired erythropoiesis. They also lead to mal-absorption and inhibition of appetite, thereby worsening micronutrients deficiency and maternal anaemia.

The principle of anaemia prevention in the study centre is regular antenatal checkups, universal deworming, haematinics supplementation and including general awareness for patients regarding their health and pregnancy care. All pregnant women receive routine daily supplementation of elemental iron and folic acid. Tablet albendazole $400 \mathrm{mg} 1$ stat is provided to all antenatal mothers attending OPD in 2nd trimester. Other interventions include HIV screening and management, health education on diet, cooking and early diagnosis and treatment of anaemia which depends on the severity and its cause as well as the gestational age of the patient. Correction of anaemia in pregnancy can be achieved either with haematinics or by blood transfusion. In our institute the decision regarding modality of anaemia correction, Fe tablets/injectable iron/blood transfusion is individualized and is based on the severity of anaemia, gestational age and associated comorbidities if any. A key component of a safe motherhood initiative is to reduce maternal mortality by half through the eradication of anaemia during pregnancy.

The management of anaemia in pregnancy is a potentially feasible and cost effective intervention to reduce maternal, foetal and perinatal mortality and morbidity. However, the actual prevalence rates of pregnancy related conditions for many individual countries and communities are not known. Thus, it was recommended at the African regional consultation on the control of anaemia in pregnancy of the WHO that simple studies of prevalence and aetiology should be undertaken. Many of the predisposing factors to anaemia in pregnancy are controllable and may lead to women becoming pregnant with anaemia; thus there is need for basic prevalence statistics to create awareness on the magnitude of anaemia in pregnancy in our environment and also to formulate strategies to reduce its adverse health consequences in order to improve maternal health and reduce poor perinatal outcome. Information on the prevalence would also be useful for the managers of health institutions and for district, provincial and national maternal, child and women's health programme development. Hence, this study aims to determine the prevalence of anaemia mainly to stress that although a lot has been done there is still a long way to go if we really want our mothers to be healthy not only in antenatal period, but also in the rest of their journey of motherhood which actually just starts with pregnancy.

The results from this study reveal the magnitude of this problem in our environment and also provide relevant data to strengthen planning on the prevention of anaemia in pregnancy, thus helping to reduce the prevalence of anaemia in pregnancy and the morbidity and mortality associated with it. The diagnosis of anaemia during booking among pregnant women is essential as it affords one the opportunity to institute interventions to prevent the complication of anaemia, especially considering the prevalent high maternal and perinatal morbidity and mortality associated with anaemia in pregnancy in the tropics. Data from the literature in developing countries have reported prevalence of anaemia in pregnancy that ranged from 35.0 to $75.0 \%$. The prevalence of anaemia in this study was $91.42 \%$, which is in the much higher range when compared to findings from other studies in Nigeria. $(2,3,4,5,6,7)$ and from countries in South Eastern Africa. $(8,9)$ The high prevalence of anaemia in this study is probably related to the low socioeconomic status of the women, which may have impact on their nutritional status and health seeking behaviour. $(3,5)$ The prevalence of anaemia in this study is much higher than the $56.0 \%$ quoted by WHO for prevalence of anaemia in Africa based on the 1988 data.(4) implying that situation is still alarming. Most of the women in this study had anaemia of mild-to-moderate severity with only $0.35 \%$ being severely anaemic. These findings are similar to the findings from Ugwuja et al(10) and those of Aluka et al(11) and Adinma et al (1) except for the absence of severe anaemia in these other studies. By WHO standard, anaemia is any $\mathrm{Hb}<11 \mathrm{gm} \%$.

The number of pregnant women with anaemia increased with increase in maternal age. These findings agree with the studies done in other parts of Nigeria. $(4,6)$ and other African countries.(9) It is generally believed that anaemia in pregnancy increases with rising parity due to repeated drain on iron stores.(1) Similarly, this study like those of other researchers. $6,5,12)$ has revealed a direct relationship between parity and anaemia as the percentage of anaemic pregnant women increased as parity increased. The possible reasons for this finding include successive deliveries with reduced interpregnancy interval for stores replenishment and deterioration of general health of the patient, also lack of interest in own health, poor socioeconomic status with increased economic burden due to increase in the number of children adds to the condition. Approximately 57.6\% of the parous women in this study had an interpregnancy interval of less than 2 years. The low level of education of the women as well as the fact that a large proportion of them were coolie workers may contribute to this trend. Similar to the findings of Bukar et al(5), the percentage of women with anaemia was higher among those with an interpregnancy interval of less than 2 years.

The history of febrile illness in the pregnant women was significantly associated with anaemia. Fever may be a proxy for malaria, a major cause of both anaemia and fever, especially in a malaria endemic area like India. Among the 26 women who tested positive for HIV $88.5 \%$ were anaemic. This is not unexpected as HIV infection is a recognized risk factor for anaemia. Suggested mechanisms include a direct effect of the virus itself, bone marrow suppression due to cytokine release and anaemia as a result of chronic inflammation or opportunistic infections, which may be further exacerbated by antiretroviral drugs like zidovudine, a component of highly active antiretroviral therapy. In our study almost all patients had the low level of education and the majority of them were in the middle-to-low social class as also noted by Bukar et al(5) and Lamina and Sorunmu.(13) in their studies. This is because though majority of the husbands of these women were in the skilled labour class, a significant percentage of them were in the unskilled labour class and only about a quarter were professionals. About $56.3 \%$ of the pregnant women were in the unskilled labour class.

The low socioeconomic status of the women may have a significant impact on their nutritional status and health seeking behaviour. Women with low socioeconomic status tend to consume diets that are low in micronutrients, animal 
protein and vitamins, but high in carbohydrate and phytates which interfere with intestinal uptake of iron and other trace minerals such as zinc and calcium. This indicates that economic empowerment of women would play a very important role in reducing the prevalence of anaemia in our environment. The percentage of women with anaemia was lowest among those that booked for antenatal care in the first trimester. This finding is in agreement with findings of Komolafe et al(4) in Ilesha and Bukar et al(5) in Gombe. This is probably due to the fact that the majority of our women booked in the second and third trimester of pregnancy. The delusional effect of pregnancy and increased fetal demand for haematopoietic factors are maximal after the first trimester. Also, underlying maternal diseases and untreated anaemia in early pregnancy are likely to worsen in the course of pregnancy. Normocytic hypochromia and microcytic hypochromia blood picture, the most common morphological types of anaemia found in this study are characteristic of iron deficiency anaemia. In developing countries like ours, anaemia in pregnancy is commonly believed to result from nutritional deficiencies especially iron.

The gold standard for making a diagnosis of iron deficiency anaemia examination of stained bone marrow aspirate for hemosiderin is invasive. Serum ferritin measurement on the other hand is costly and largely not available in most centers in the country and is elevated in the presence of inflammation, which is not uncommon in our environment. The high percentage of iron deficiency in this study could be as a result of the large proportion of women of low socioeconomic class. Iron needs increase greatly during the second and third trimesters of pregnancy and that was when maximum women that were certain of their gestational age booked for antenatal care. Following multivariate analysis, the risk factors in this study were multiparity, lack of education and awareness, noncompliance to Fe tablets, GA at booking and low social class. This shows that the interventions to prevent and treat anaemia during the antenatal care visits are appropriate and need to be pursued vigorously.

\section{CONCLUSION}

This study has revealed that anaemia in pregnancy is still highly prevalent in our environment. The study has also revealed that the most important risk factors for anaemia in pregnancy in this center are socioeconomic status of women, multiparity and irregular antenatal visits. The commonest red cell blood pictures among the anaemic clients were microcytic hypochromia and normocytic hypochromia, which are indicative of iron deficiency anaemia. Hence, public health campaigns to create awareness about the importance of early booking for antenatal care are recommended. This will provide opportunity for early detection and treatment of anaemia as well as the timely institution of preventive measures like haematinics and deworming.

The socioeconomic situation of the womenfolk should be improved by economically empowering them through provision of salary paying jobs by government since majority of these women are educated. Also efforts should be made towards HIV prevention and treatment in the state. Further studies are needed to identify specific aetiological factors. A study of the prevalence and pattern of anaemia in the community is also recommended. This would aid in planning healthcare services, in reducing the attendant morbidity and mortality and also improving the wellbeing of women in the society in general.

\section{REFERENCES}

1. Vivek RG, Halappanavar AB, Vivek PR, et al. Prevalence of anaemia and its epidemiological. Determinants in Pregnant Women 2012;5(3):216-23.

2. WHO/CDC, worldwide prevalence of anaemia 19932005. WHO global database on anaemia. Geneva, Switzerland: WHO Press 2008;2:3-5.

3. Salhan S, Tripathi V, Singh R, et al. Evaluation of haematological parameters in partial exchange and packed cell transfusion in treatment of severe anaemia in pregnancy. Anaemia Article ID 608658, 2012;2012:pp 7.

4. Aikawa R, Khan NC, Sasaki S, et al. Risk factors for irondeficiency anaemia among pregnant women living in rural Vietnam. Public Health Nutrition 2006;9(4):443-8.

5. Haidar J. Prevalence of anaemia, deficiencies of iron and folic acid and their determinants in Ethiopian women. Journal of Health Population and Nutrition 2010;28(4):359-68.

6. Baker SJ, DeMaeyer EM. Nutritional anaemia: its understanding and control with special reference to the work of the world health organization. American Journal of Clinical Nutrition1979;32(2):368-417.

7. Toteja GS, Singh P, Dhillon BS, et al. Prevalence of anaemia among pregnant women and adolescent girls in 16 districts of India. Food and Nutrition Bulletin 2006;27(4):311-5.

8. Khalafallah AA, Dennis AE. Iron deficiency anaemia in pregnancy and postpartum: pathophysiology and effect of oral versus intravenous iron therapy. Journal of Pregnancy Article ID 630519, 2012;2012:pp 10.

9. Raza N, Sarwar I, Munazza B, et al. Assessment of iron deficiency in pregnant women by determining iron status. Journal of Ayub Medical College Abbottabad2011;23(2):36-40.

10. Ugwuja E, Akubugwo E, Ibiam $\mathrm{U}$, et al. Impact of maternal iron deficiency and anaemia on pregnancy \& its outcome in Nigerian population. Internet Journal of Nutrition and Wellness 2010;10(1):1-10.

11. Aluka C, Amadi AN, Kamnu CI, et al. Anaemia in pregnancy in Abia state university teaching hospital Aba. Journal of Medical Investigation and Practice 2001;2: 58-61.

12. Esmat B, Mohammad R, Behnam S, et al. Prevalence of iron deficiency anaemia among Iranian pregnant women; a systematic review and meta-analysis. Journal of Reproduction and Infertility 2010;11(1):17-24.

13. Makhoul Z, Taren D, Duncan B, et al. Risk factors associated with anaemia, iron deficiency and iron deficiency anaemia in rural Nepali pregnant women. Southeast Asian Journal of Tropical Medicine and Public Health 2012;43(3):735-46. 